OPEN ACCESS

Edited by:

Jiang Helong,

Nanjing Institute of Geography and Limnology (CAS), China

Reviewed by: Carl Lamborg,

University of California, Santa Cruz, United States

Susan Tandy

Rothamsted International,

United Kingdom

*Correspondence:

Vera I. Slaveykova

vera.slaveykova@unige.ch

Specialty section:

This article was submitted to

Biogeochemical Dynamics,

a section of the journal

Frontiers in Environmental Science

Received: 18 April 2019

Accepted: 27 May 2019

Published: 10 June 2019

Citation:

Slaveykova VI (2019) Biogeochemical

Dynamics Research in the Anthropocene.

Front. Environ. Sci. 7:90.

doi: 10.3389/fenvs.2019.00090

\section{Biogeochemical Dynamics Research in the Anthropocene}

\author{
Vera I. Slaveykova* \\ Environmental Biogeochemistry and Ecotoxicology, Department F.-A. Forel for Environmental and Aquatic Sciences, School \\ of Earth and Environmental Sciences, Faculty of Sciences, University of Geneva, Geneva, Switzerland
}

The present paper provides a perspective on selected key issues driving inquiry in biogeochemical dynamics research of Twenty-first century, which could contribute to filling of knowledge gaps toward development of the systems biogeochemistry approach. The specific focus is on understanding of the multiscale processes and effects involving elements and chemical compounds, their interactions with other environmental variables, as well as the development of integrative quantitative models and their validation. The special attention is paid on the necessity to decipher the biogeochemical dynamics of the novel entities and combinations of inorganic and/or organic chemicals in the environment, as well as their critical linkages and feedbacks with major nutrient cycles, the interplays with climate change and other anthropogenic stressors. Taking advantage of rapidly developing omics approaches and stable isotopes of non-traditional metals as well as the synergies arising from their integration in the biogeochemical modeling are discussed together with their potential to transform biogeochemical studies and push toward new frontiers in biogeochemical dynamics knowledge.

\footnotetext{
Keywords: biogeochemical cycles, bioavailability, stable isotopes, omics, trace elements, nanoparticles, microplastics, organic contaminants
}

Understanding how our planet works as an integrated physical, chemical, and biological system, how human activities and global change perturbed its functioning, and what would be the implications for the Earth's life and human society is central in the modern biogeosciences. Focusing on the Earth as a chemical system and exploring the dynamic interactions of the elements and compounds with biological and geological components and their alterations, the biogeochemical dynamics provides a knowledge, which is vital for our society, particularly in the light of the ongoing climate change and growing anthropogenic pressures.

At the onset of the Anthropocene (Crutzen, 2002), Homo sapiens became a major driver for environmental change at an unprecedented rate, which could threaten the Earth as a life support system. The concept of planetary boundaries, which defines the safe operating space for humanity was thus proposed (Rockström et al., 2009; Steffen et al., 2015). The planetary boundaries relate to the critical Earth's systems/processes and identify the key limits which if crossed could push the Earth system toward a new undesirable state, "less hospitable to the development of 
human societies" (Steffen et al., 2015). Among the nine planetary boundaries, those related with biogeochemical flows, phosphorus (P) and nitrogen $(\mathrm{N})$ are in the high-risk zone, while those concerning the aerosol loading and novel chemical entities cannot be yet quantified given the lack of sufficient knowledge (Steffen et al., 2011, 2018). Indeed, the setting of science-informed planetary boundaries is recognized to be very challenging and to require advanced knowledge about the various Earth System processes (Diamond et al., 2015; Steffen et al., 2018). An extension of the planetary boundaries concept to planetary boundary windows has been suggested to account for the uncertainties around the individual boundaries and their interactions (Nash et al., 2017). In such a context, the understanding of the biogeochemical dynamics of the multifaceted Earth (sub-) systems, of the underlying processes and feedbacks with human activity and global change, is a central topic of research in the environmental sciences.

The biogeochemical dynamics is about the movement and transformation of the elements and chemical compounds in the environment. It is an "intersection" were different disciplinary perspectives meet to address the complex nature of the interactions between the chemical, biological and geological components determining the Earth chemical dynamics. Part of broader biogeosciences, biogeochemistry shares common fundamental endeavors as previously discussed (Acocella, 2015; Eglinton, 2015). Here I rather focus on selected issues where I believe the process-oriented knowledge has a potential to lead to sound progress in the understanding of the biogeochemical dynamics of the environment.

\section{MOVING TOWARD MULTISCALE SYSTEMS BIOGEOCHEMISTRY}

Biogeochemistry is a systems science "par excellence." Studies focus on the global biogeochemical cycles of nutrients (e.g., C, N, P, S, etc.), essential (e.g., Fe, Se, Zn, etc.) and toxic (e.g., $\mathrm{Cd}, \mathrm{Hg}, \mathrm{Pb}$, etc.) trace elements. These studies lead to the goal of establishing the large-scale inventories and flows between the environmental spheres, exploring the humaninduced perturbation and climatic feedbacks shaped the modern biogeochemistry over the past decades, and will continue to mark the road for future research.

Biogeochemical cycles and flows involve a myriad of species formed by complex interactions of the elements with various abiotic and biotic components. Given the different reactivity of these species, knowledge on elemental speciation is central for the understanding of their distribution, mobility, and biological outcome in the environment. Many of the transformation pathways are biologically mediated, therefore understanding the abiotic-biotic transformation linkages and the incorporation of the bioavailability concept (Slaveykova and Wilkinson, 2005) in biogeochemical dynamics research will be an important step forward. A significant progress in studying the major transformations processes has been achieved, including complexation, oxidation/reduction, methylation/demethylation etc., of the elements and their compounds. However, such knowledge is rarely taken into consideration at larger or global scales.

An exciting scientific endeavor of the Twenty-First century biogeochemistry will be to develop further understanding of the chemical dynamics of the Earth through the systems approach and to link the observations at different scales. Although there is recognition of the importance of the systems science for the understanding of how the parts of the system function and how they work in a broader system setting in systems ecology (Evans et al., 2012), the systems approaches in global change and biogeochemistry research are rather rare (Smith et al., 2012). The bridging of the processes at the molecular level with the elemental and compound flows at the global level is thus one of the biggest challenge in modern biogeochemistry given the large spatial and temporal differences, as well as the great complexity of biogeochemical processes. Pressing needs thus exist to fill the significant knowledge gaps, including the understanding of the multiscale processes and effects involving elements and chemical compounds, their interactions with other environmental variables, as well as the development of integrative quantitative models and their validation.

\section{UNDERSTANDING THE BIOGEOCHEMICAL DYNAMICS OF "NOVEL ENTITIES"}

The appearance of novel entities and combinations of inorganic and/or organic chemicals in the environment is a specific feature of the Anthropocene (Crutzen, 2002). Micro- and nanoplastics, purposely engineered nanomaterials, and high diversity of synthetic organic compounds represent some of the most striking examples of such novel chemical entities, and specific markers of the Anthropocene. The unprecedented rate of their release in the environment and their diversity are so important, that they surpassed other drivers of global environmental change (Bernhardt et al., 2017). For example, the amount of microplastics in the ocean is estimated to increase by a factor of 4 in 2060 (Isobe et al., 2019). As persistent, long-range transported and bioaccumulative pollutants with a potential to cause adverse effects, the microplastics were suggested to be a possible "planetary boundary threat" (Galloway et al., 2017), however the likely disruptive effect on the life supporting processes at global level are still highly uncertain. Similarly, significant advances have been achieved in the understanding of the behavior and possible detrimental effects of metal-containing nanoparticles (Ivask et al., 2014; von Moos and Slaveykova, 2014) and their transformations under specific settings (Levard et al., 2012; Espinasse et al., 2018). However, a larger-scale biogeochemical perspective is still lacking.

A major challenge remains to understand the biogeochemical dynamics of such man-made compounds, as well as their critical linkages and feedbacks with major nutrient cycles, and interactions/feedbacks with climate change and other anthropogenic pressures. The high diversity of the chemical compounds, complex pathways in the environment and the multitude of possible impacts may result in synergistic, additive, 
and antagonistic interactions (Fischer et al., 2013; Cheloni and Slaveykova, 2018). A more systematic approach taking into consideration the combined pressure of multiple stressors (Kaushal et al., 2018) and reconceptualization of distribution and transformation processes of chemical mixtures was thus advocated to be critical to ecosystem management (Hayes and Hansen, 2017). Going beyond by further exploring the novel entities dynamics in the environment within the context of climate change and increasing anthropogenic pressure on the environment will be a central topic for the future.

\section{TAKING ADVANTAGE OF MULTI-OMICS APPROACHES}

One of the exciting frontiers in biogeochemical dynamics is the investigation of how living organisms influence the elements and chemical pathways in the environment, and in turn, how the element species affect living organisms. The systems biology approach is more frequently employed to better understand how environmental change impacts marine microorganisms (Mock et al., 2016). For example, the global pool of available metabolic functions was highlighted as a major driver of formation of biogeochemical gradients in the ocean (Coles et al., 2017). Metatranscriptomics made it possible to establish a global ocean atlas of planktonic eukaryotic genes across four organismal size fractions and to explore the roles of marine eukaryotes in ocean biogeochemistry (Carradec et al., 2018). A meta-omic analysis revealed key microbial populations degrading the carbon sequestered in permafrost and highlighted lineages with the production of greenhouse gases (Woodcroft et al., 2018).

The omics have the potential to uncover the perturbation of key biogeochemical processes induced by the chemical contaminants. The omics approaches are largely used in ecotoxicology and stress ecology to reveal the novel molecular mechanisms of toxicity and to assess chemical effects at different levels of biological complexity (Beauvais-Flück et al., 2017; Zhang et al., 2018). For example, the omics provided new insights on the effects of $\mathrm{Hg}$ compounds on cellular processes in individual organisms (Beauvais-Flück et al., 2017; Dranguet et al., 2017a) and in a biofilm community (Dranguet et al., 2017b). Multi-omics based approaches unraveled the microbial arsenic transformation processes, and their connections to other biogeochemical cycle (Zhu et al., 2017). These selected examples revealed that rapidly developing omics approaches have a potential to transform biogeochemical studies. However, the question how to use such multidimensional information and to link with specific processes, constraining cycles and flows taking place at large temporal and spatial scales represent important current challenges in biogeochemistry.

The integration of the omics data with established biogeochemical models is another important challenge. Existing models that explicitly consider genes and make predictions at the population or ecosystem levels were grouped in three general approaches, i.e., metabolic flux, gene-centric and agentbased (Kreft et al., 2017). It was further argued that "adopting an integrated modeling approach to biogeochemistry and environmental genomics data is a powerful means of exploring the nexus between microbial ecology and geochemistry" (Reed et al., 2014). However, only a few examples of such integrative approaches in biogeochemical context can be found. A model integrating aquatic biogeochemistry and multi-omics information has shed light on the metabolic networks coupling $\mathrm{C}, \mathrm{S}$, and $\mathrm{N}$ transformations across a sea redox gradient (Louca et al., 2016). Integrating gene and population dynamics into biogeochemical models has the potential to improve predictions of the community response under altered scenarios to guide remediation efforts (Arora-Williams et al., 2018). Looking forward to the years to come, the role of the omics in biogeochemical research will increase. Therefore, the synergies arising from integrating the omics with process-oriented data in biogeochemical modeling will allow to gain deeper insights into key environmental systems and their perturbations.

\section{TAKING ADVANTAGES OF STABLE ISOTOPES APPROACHES}

Stable isotope variations of light elements, such as $\delta^{13} \mathrm{C}$, $\delta^{15} \mathrm{~N}, \delta^{18} \mathrm{O}$, and $\delta^{34} \mathrm{~S}$ and their ratios are employed, since decades, as source and process tracers to understand numerous interactions in complex environmental systems (SanchezCarrillo and Alvarez-Cobelas, 2018). Tremendous progress has been made in high-precision stable isotope analysis of nontraditional heavy isotopes of elements that are essential for life (e.g., Fe, Cu, Ni, Mo, Zn) or toxic (e.g., Hg, Pb). Such analyses have made it possible to gain new insights into elemental transformations, their interactions with leaving systems, as well as their sources and sinks (Wiederhold, 2015). For example, the isotopic composition of dissolved and particulate forms of iron revealed that the photochemical and biological reduction and dissolution of particulate iron in the surface ocean are key processes determining Fe bioavailability to marine biota (Ellwood et al., 2015). Since different biotic and abiotic processes could cause metal isotope fractionation (Wiederhold, 2015), the use of mass-dependent and mass-independent fractionation as well as multidimensional isotope tracing open new avenues for disentanglement of elemental transformation pathways. The "isoscapes" concept was also proposed for the understanding of the processes on Earth systems through isotope mapping (West et al., 2010). Future methodological developments and more affordable analytical costs of the stable isotopes of non-traditional metals will make their use much wider. Broader use will of course pave the route toward novel discoveries and push toward the emergence of unexpected dimensions of knowledge and thus will shape the future of Earth systems chemical dynamics research.

Incorporation of stable isotopes and isotopic fractionation data in the existing biogeochemical models will also be an important step onward, since it would give an opportunity to study the cycling, to simulate perturbation experiments (e.g., under different global change scenarios) and thus to track the key processes over large time scales. A recent example is the insertion of mercury speciation and isotopic fractionation into the global ocean biogeochemistry model, which allowed exploration and understanding of the importance of different processes in the $\mathrm{Hg}$ cycle in the oceans (Archer and Blum, 2018). 
Biogeochemistry research in the Anthropocene has a great potential, but also an intimidating task to guide and contribute with a knowledge necessary to develop the scientifically sound environmental management practices to reverse current trends of environmental degradation and instead promote planetary wellbeing, secure the integrity of the Earth's life-support systems and sustainable future.

\section{DATA AVAILABILITY}

No datasets were generated or analyzed for this study.

\section{REFERENCES}

Acocella, V. (2015). Grand challenges in Earth science: research toward a sustainable environment. Front. Earth Sci. 3:68. doi: 10.3389/feart.2015.00068

Archer, D. E., and Blum, J. D. (2018). A model of mercury cycling and isotopic fractionation in the ocean. Biogeosciences 15, 6297-6313. doi: 10.5194/bg-15-6297-2018

Arora-Williams, K., Olesen, S. W., Scandella, B. P., Delwiche, K., Spencer, S. J., Myers, E. M., et al. (2018). Dynamics of microbial populations mediating biogeochemical cycling in a freshwater lake. Microbiome 6:16. doi: 10.1186/s40168-018-0556-7

Beauvais-Flück, R., Slaveykova, V. I., and Cosio, C. (2017). Cellular toxicity pathways of inorganic and methyl mercury in the green microalga Chlamydomonas reinhardtii. Sci. Rep. 7:8034. doi: 10.1038/s41598-017-08515-8

Bernhardt, E. S., Rosi, E. J., and Gessner, M. O. (2017). Synthetic chemicals as agents of global change. Front. Ecol. Environ. 15, 84-90. doi: 10.1002/fee.1450

Carradec, Q., Pelletier, E., Da Silva, C., Alberti, A., Seeleuthner, Y., Blanc-Mathieu, R., et al. (2018). A global ocean atlas of eukaryotic genes. Nat. Commun. 9:13. doi: 10.1038/s41467-017-02342-1

Cheloni, G., and Slaveykova, V. I. (2018). Combined effects of trace metals and light on photosynthetic microorganisms in aquatic environment. Environments 5:81. doi: 10.3390/environments5070081

Coles, V. J., Stukel, M. R., Brooks, M. T., Burd, A., Crump, B. C., Moran, M. A., et al. (2017). Ocean biogeochemistry modeled with emergent trait-based genomics. Science 358, 1149-1154. doi: 10.1126/science.aan5712

Crutzen, P. J. (2002). Geology of mankind. Nature 415:23. doi: 10.1038/415023a

Diamond, M. L., de Wit, C. A., Molander, S., Scheringer, M., Backhaus, T., Lohmann, R., et al. (2015). Exploring the planetary boundary for chemical pollution. Environ. Int. 78, 8-15. doi: 10.1016/j.envint.2015.02.001

Dranguet, P., Cosio, C., Le Faucheur, S., Beauvais-Flück, R., Freiburghaus, A., Worms, I. A. M., et al. (2017a). Transcriptomic approach for assessment of the impact on microalga and macrophyte of in-situ exposure in river sites contaminated by chlor-alkali plant effluents. Water Res. 121, 86-94. doi: 10.1016/j.watres.2017.05.020

Dranguet, P., Cosio, C., Le Faucheur, S., Hug Peter, D., Loizeau, J. L., Ungureanu, V. G., et al. (2017b). Biofilm composition in the Olt River (Romania) reservoirs impacted by a chlor-alkali production plant. Environ. Sci. Processes Impacts 19, 687-695. doi: 10.1039/C7EM00033B

Eglinton, T. (2015). Grand challenges in biogeoscience. Front. Earth Sci. 3:39. doi: 10.3389/feart.2015.00039

Ellwood, M. J., Hutchins, D. A., Lohan, M. C., Milne, A., Nasemann, P., Nodder, S. D., et al. (2015). Iron stable isotopes track pelagic iron cycling during a subtropical phytoplankton bloom. Proc. Natl. Acad. Sci. U.S.A. 112, E15-E20. doi: $10.1073 /$ pnas.1421576112

Espinasse, B. P., Geitner, N. K., Schierz, A., Therezien, M., Richardson, C. J., Lowry, G. V., et al. (2018). Comparative persistence of engineered nanoparticles in a complex aquatic ecosystem. Environ. Sci. Technol. 52, 4072-4078. doi: 10.1021 /acs.est.7b06142

Evans, M., R., Norris, K., J., and Benton, T. G. (2012). Predictive ecology: systems approaches. Philos. Transact. R. Soc. B. Biol. Sci. 367, 163-169. doi: $10.1098 /$ rstb.2011.0191

\section{AUTHOR CONTRIBUTIONS}

The author confirms being the sole contributor of this work and has approved it for publication.

\section{ACKNOWLEDGMENTS}

The reflection that resulted in this perspective article has been possible in part because of the financial support of the Swiss National Science Foundation (Grant number IZSEZ0_180186).

Fischer, B. B., Pomati, F., and Eggen, R. I. (2013). The toxicity of chemical pollutants in dynamic natural systems: the challenge of integrating environmental factors and biological complexity. Sci. Total Environ. 449, 253-259. doi: 10.1016/j.scitotenv.2013.01.066

Galloway, T. S., Cole, M., and Lewis, C. (2017). Interactions of microplastic debris throughout the marine ecosystem. Nat. Ecol. Evol. 1:0116. doi: 10.1038/s41559-017-0116

Hayes, T. B., and Hansen, M. (2017). From silent spring to silent night: agrochemicals and the anthropocene. Elementa Sci. Anthropocene 5:24. doi: $10.1525 /$ elementa.246

Isobe, A., Iwasaki, S., Uchida, K., and Tokai, T. (2019). Abundance of nonconservative microplastics in the upper ocean from 1957 to 2066. Nat. Commun. 10:417. doi: 10.1038/s41467-019-08316-9

Ivask, A., Juganson, K., Bondarenko, O., Mortimer, M., Aruoja, V., Kasemets, K., et al. (2014). Mechanisms of toxic action of Ag, $\mathrm{ZnO}$ and $\mathrm{CuO}$ nanoparticles to selected ecotoxicological test organisms and mammalian cells in vitro: a comparative review. Nanotoxicology 8, 57-71. doi: 10.3109/17435390.2013.855831

Kaushal, S. S., Gold, A. J., Bernal, S., Johnson, T. A. N., Addy, K., Burgin, A., et al. (2018). Watershed "chemical cocktails': forming novel elemental combinations in Anthropocene fresh waters. Biogeochemistry 141, 281-305. doi: 10.1007/s10533-018-0502-6

Kreft, J. U., Plugge, C. M., Prats, C., Leveau, J. H. J., Zhang, W., and Hellweger, F. L. (2017). From genes to ecosystems in microbiology: modeling approaches and the importance of individuality. Front. Microbiol. 8:2299. doi: $10.3389 /$ fmicb. 2017.02299

Levard, C., Hotze, E. M., Lowry, G. V., and Brown, G. E. (2012). Environmental transformations of silver nanoparticles: impact on stability and toxicity. Environ. Sci. Technol. 46, 6900-6914. doi: 10.1021/es2037405

Louca, S., Hawley, A. K., Katsev, S., Torres-Beltran, M., Bhatia, M. P., Kheirandish, S., et al. (2016). Integrating biogeochemistry with multiomic sequence information in a model oxygen minimum zone. Proc. Natl. Acad. Sci. U.S.A. 113, E5925-E5933. doi: 10.1073/pnas.1602897113

Mock, T., Daines, S. J., Geider, R., Collins, S., Metodiev, M., Millar, A. J., et al. (2016). Bridging the gap between omics and earth system science to better understand how environmental change impacts marine microbes. Glob. Change Biol. 22, 61-75. doi: 10.1111/gcb.12983

Nash, K. L., Cvitanovic, C., Fulton, E. A., Halpern, B. S., Milner-Gulland, E. J., Watson, R. A., et al. (2017). Planetary boundaries for a blue planet. Nat. Ecol. Evol. 1, 1625-1634. doi: 10.1038/s41559-017-0319-Z

Reed, D. C., Algar, C. K., Huber, J. A., and Dick, G. J. (2014). Gene-centric approach to integrating environmental genomics and biogeochemical models. Proc. Natl. Acad. Sci. U.S.A. 111, 1879-1884. doi: 10.1073/pnas.1313713111

Rockström, J., Steffen, W., Noone, K., Persson, A., Chapin, F. S., Lambin, E. F., et al. (2009). A safe operating space for humanity. Nature 461:472. doi: $10.1038 / 461472 \mathrm{a}$

Sanchez-Carrillo, S., and Alvarez-Cobelas, M. (2018). Stable isotopes as tracers in aquatic ecosystems. Environ. Rev. 26, 69-81. doi: 10.1139/er-2017-0040

Slaveykova, V. I., and Wilkinson, K. J. (2005). Predicting the bioavailability of metals and metal complexes: critical review of the biotic ligand model. Environ. Chem. 2, 9-24. doi: 10.1071/EN04076 
Smith, P., Albanito, F., Bell, M., Bellarby, J., Blagodatskiy, S., Datta, A., et al. (2012). Systems approaches in global change and biogeochemistry research. Philos. Trans. R Soc. B Biol. Sci. 367, 311-321. doi: 10.1098/rstb.20 11.0173

Steffen, W., Persson, A., Deutsch, L., Zalasiewicz, J., Williams, M., Richardson, K., et al. (2011). The anthropocene: from global change to planetary stewardship. Ambio 40, 739-761. doi: 10.1007/s13280-011-0185-x

Steffen, W., Richardson, K., Rockström, J., Cornell, S. E., Fetzer, I., Bennett, E. M., et al. (2015). Planetary boundaries: guiding human development on a changing planet. Science 347:1259855. doi: 10.1126/science. 1259855

Steffen, W., Rockström, J., Richardson, K., Lenton, T. M., Folke, C., Liverman, D., et al. (2018). Trajectories of the earth system in the Anthropocene. Proc. Natl. Acad. Sci. U.S.A. 115, 8252-8259. doi: 10.1073/pnas.1810141115

von Moos, N., and Slaveykova, V. I. (2014). Oxidative stress induced by inorganic nanoparticles in bacteria and aquatic microalgae-state of the art and knowledge gaps. Nanotoxicology 8, 605-630. doi: 10.3109/17435390.2013.809810

West, J. B., Bowen, G. J., Dawson, T. E., and Tu, K. P. (2010). Isoscapes: Understanding Movement, Patternand Process on EarthThrough Isotope Mapping. NewYork, NY: Springer.

Wiederhold, J. G. (2015). Metal stable isotope signatures as tracers in environmental geochemistry. Environ. Sci. Technol. 49, 2606-2624. doi: $10.1021 /$ es504683e
Woodcroft, B. J., Singleton, C. M., Boyd, J. A., Evans, P. N., Emerson, J. B., Zayed, A. A. F., et al. (2018). Genome-centric view of carbon processing in thawing permafrost. Nature 560, 49-54. doi: 10.1038/s41586-0180338-1

Zhang, X., Xia, P., Wang, P., Yang, J., and Baird, D. J. (2018). Omics advances in ecotoxicology. Environ. Sci. Technol. 52, 3842-3851. doi: 10.1021/acs.est.7b06494

Zhu, Y. G., Xue, X. M., Kappler, A., Rosen, B. P., and Meharg, A. A. (2017). Linking genes to microbial biogeochemical cycling: lessons from arsenic. Environ. Sci. Technol. 51, 7326-7339. doi: 10.1021/acs.est.7b 00689

Conflict of Interest Statement: The author declares that the research was conducted in the absence of any commercial or financial relationships that could be construed as a potential conflict of interest.

Copyright $\odot 2019$ Slaveykova. This is an open-access article distributed under the terms of the Creative Commons Attribution License (CC BY). The use, distribution or reproduction in other forums is permitted, provided the original author $(s)$ and the copyright owner(s) are credited and that the original publication in this journal is cited, in accordance with accepted academic practice. No use, distribution or reproduction is permitted which does not comply with these terms. 